\title{
Pathologic Correlation of PET-CT Based Auto Contouring for Radiation Planning in Lung Cancer
}

\author{
S. E. Fogh \\ Thomas Jefferson University and Hospitals
}

A. Farach

Jefferson Medical College

C. Intenzo

Thomas Jefferson University and Hospitals

R. Axelrod

Thomas Jefferson University and Hospitals

P. McCue

Thomas Jefferson University and Hospitals. Follow this and additional works at: https://jjc.jefferson.edu/bodinejournal

Part of the Oncology Commons

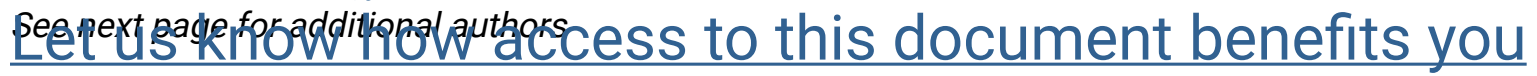

\section{Recommended Citation}

Fogh, S. E.; Farach, A.; Intenzo, C.; Axelrod, R.; McCue, P.; Harper, A.; Nelson, A.; and Werner-Wasik, M (2010) "Pathologic Correlation of PET-CT Based Auto Contouring for Radiation Planning in Lung Cancer," Bodine Journal: Vol. 3 : Iss. 1 , Article 30.

DOI: https://doi.org/10.29046/TBJ.003.1.029

Available at: https://jdc.jefferson.edu/bodinejournal/vol3/iss1/30

This Article is brought to you for free and open access by the Jefferson Digital Commons. The Jefferson Digital Commons is a service of Thomas Jefferson University's Center for Teaching and Learning (CTL). The Commons is a showcase for Jefferson books and journals, peer-reviewed scholarly publications, unique historical collections from the University archives, and teaching tools. The Jefferson Digital Commons allows researchers and interested readers anywhere in the world to learn about and keep up to date with Jefferson scholarship. This article has been accepted for inclusion in Bodine Journal by an authorized administrator of the Jefferson Digital Commons. For more information, please contact: JeffersonDigitalCommons@jefferson.edu. 


\section{Pathologic Correlation of PET-CT Based Auto Contouring for Radiation Planning}

in Lung Cancer

\section{Authors}

S. E. Fogh, A. Farach, C. Intenzo, R. Axelrod, P. McCue, A. Harper, A. Nelson, and M Werner-Wasik 


\title{
Pathologic Correlation of PET-CT Based Auto Contouring for Radiation Planning in Lung Cancer
}

\author{
Fogh, S.E., ${ }^{1}$ Farach, A., ${ }^{2}$ Intenzo, C., ${ }^{3}$ Axelrod, R., ${ }^{3}$ McCue, P., ${ }^{4}$ Harper, A., ${ }^{5}$ Nelson, A., ${ }^{6}$ Werner-Wasik, M. ${ }^{1}$ \\ ${ }^{1}$ Department of Radiation Oncology, Thomas Jefferson University and Hospitals, Philadelphia, PA \\ 2Jefferson Medical College, Thomas Jefferson University, Philadelphia, PA \\ ${ }^{3}$ Department of Medical Oncology, Thomas Jefferson University and Hospitals, Philadelphia, PA \\ ${ }^{4}$ Department of Pathology, Thomas Jefferson University and Hospitals, Philadelphia, PA \\ ${ }^{5}$ Department of Radiology, Thomas Jefferson University and Hospitals, Philadelphia, PA \\ ${ }^{6}$ MiMVista Corporation, Cleveland, Ohio
}

\section{Purpose/Objective(s)}

Radiation therapy in lung cancer relies on CT and functional imaging (FDG-PET) to delineate tumor volumes. Semi-automatic contouring tools have been developed for PET to improve on the inter-observer bias of manual contouring and intrinsic differences in imaging equipment. A common method involves using a threshold at a given percentage of the max activity, which may be less accurate with smaller tumors and tumors with low source to background ratio. To overcome this deficiency, a gradient algorithm, which detects changes in image counts at the border of the tumor, has been developed. Few studies have correlated these methods to pathological specimens.

\section{Materials/Methods}

Thirty-three patients with lung cancer underwent lobectomy and had available PET imaging prior to resection. We retrospectively contoured tumors using 1) a constant threshold algorithm which included all voxels within a defined region with counts exceeding $34 \%$ of the maximum counts in that region, and 2) a commerciallyavailable gradient-based "PET edge" tool. Largest tumor diameters from both methods were compared to the largest diameter from gross pathology reports using Pearson's correlation coefficient (CC).

\section{Results}

CC between maximal diameter contoured with the gradient tool or $34 \%$ percent threshold and tumor diameter were 0.79 and 0.82 , respectively. The median largest tumor diameters were as follows: from pathology reports, $2.1 \mathrm{~cm}$ (range 0.6-9.5 cm); from threshold method, $2.9 \mathrm{~cm}$ (range $2.1-10.7 \mathrm{~cm}$ ); from gradient tool, $2.8 \mathrm{~cm}$ (range 1.7-10.4 cm). Tumor diameters $\leq 2.1$ had a poor correlation with PET derived diameters (CC $=0.19$ for gradient method and 0.31 for threshold method). Tumors larger than $4 \mathrm{~cm}$ had the best correlation with automatic contouring techniques ( $\mathrm{CC}=0.87$ for gradient method and 0.83 with threshold method). The percent threshold method was more highly correlated with pathological tumor size in tumors with SUVs less than 2.5 (CC $=0.75$ for gradient technique and 0.92 for threshold technique) but no difference between the techniques was noted in tumors with SUVs of 2.5 or greater. Adenocarcinoma histology was more highly correlated with both the gradient and threshold method ( $\mathrm{CC}=0.92$ and 0.93 respectively) vs. other histologies ( 0.04 and 0.09 respectively). The Average Percent Error using the gradient method was $28 \%+/-58 \%$ and $47.8 \%+/-62 \%$ for threshold method $(P=0.0003)$.

\section{Conclusion}

Maximal diameters obtained with gradient and threshold methods were correlated with maximal pathologic diameter. The gradient method had significantly less percent error then the threshold method. The threshold method demonstrated stronger correlation to patholicic diameter in tumors with SUVs below 2.5. Histology, size and SUV influenced correlation to pathology. 